\title{
21
}

\section{Group Report: How Do Heuristics Mediate the Impact of Law on Behavior?}

\author{
Daniel G. Goldstein, Rapporteur
}

\author{
Hal R. Arkes, Martin Beckenkamp, Robert Cooter, \\ Robert C. Ellickson, Christoph Engel, Chris Guthrie, \\ Ralph Hertwig, Stephanie Kurzenhäuser, and Elke U. Weber
}

\begin{abstract}
How do people make decisions about legally relevant actions? In this group report we look at the demand side of legal information, the supply side of legal information, and how the law reaches its addressees through a range of real-world examples familiar to ordinary citizens.

The first part of the report is concerned with the issue of how people decide to act under laws. Since optimization is impossible in ordinary minds, we speculate about what other processes may be at play in determining behavior. In the second part, we look at how people learn about laws that may govern behavior. Since modern law is too massive for any individual to comprehend fully, we aim to understand how people figure out what the laws are, and when to undertake research into the law. The third part outlines, by way of examples, ways by which actual laws make their way to their addressees. We conclude by exploring policy considerations that present themselves when viewing law's impact on behavior as mediated by heuristics.
\end{abstract}

\section{INTRODUCTION}

How do people make decisions about legally relevant actions? Rational choice theory has been the dominant source of assumptions about the actions of people impacted by laws (Posner 2003; Cooter and Ulen 2004), from ordinary citizens who face a broad range of private and criminal laws, to judicial agents (such as judges, prosecutors, attorneys, or jury members) who need to follow a range of substantive and procedural laws. In the rational choice framework, legal rules are modeled as restrictions. Actors are assumed to maximize preferences they 
would hold in an institution-free state of nature, given the restrictions of the law. The last half-century has seen the arrival of alternative models of human information processing, which make assumptions about human judgment and decision processes that take into consideration the psychological processes underlying human cognition. In the 1950s, Herbert Simon's notion of bounded rationality suggested replacing the view of the mind as having unlimited resources with one that respects real-world constraints of limited time, knowledge, and computational might (Simon 1957). In the 1970s, Tversky and Kahneman's "heuristics-and-biases" research program strove to uncover the heuristics with which people make decisions (for a summary account, see Kahneman and Tversky 2000). In the 1980s and 1990s, Payne, Bettman, and Johnson's Adaptive Decision Maker program $(1993,1997)$ and Gigerenzer and colleagues' Adaptive Behavior and Cognition initiative (1999) formalized cognitive heuristics, allowing them to be simulated on computers, analyzed mathematically, and detected in process data. As a result, psychologists are now equipped to understand how cognitive heuristics will perform in various environments.

Heuristic information processing characteristically uses less information to arrive at decisions, and capitalizes on past experience and expertise within the decision domain to select wisely from among available options - the resulting decisions can be as good as or better than those obtained by more comprehensive cost-benefit calculations. This relative advantage of heuristics (equal quality at reduced effort) is achieved by their situational (content and context) specificity; that is, the success of a specific heuristic is highly contingent on multiple aspects of the decision environment, and a useful theory of heuristic processing thus needs to specify the environmental conditions or cues that should trigger specific heuristics (Payne et al. 1992; Gigerenzer et al. 1999).

In this chapter, we consider the implications of making assumptions about heuristic judgment and decision rules of people in legal contexts. We limit ourselves largely to an examination of the behavior of ordinary citizens rather than of agents of the law, since the latter topic is covered elsewhere in this volume. We further confine our analysis to what we will call "legally relevant decisions" or decisions that have the potential to give rise to legal rights or duties.

Many decisions are legally irrelevant. When an individual decides to get up at 7:00 rather than 8:00, or to drink coffee rather than tea, such choices are highly unlikely to have any legal implications. (In unusual circumstances, even these mundane decisions can involve legal rights. For example, if an individual is burned while drinking unreasonably hot coffee from McDonald's, she might have a quite viable tort claim against the company.)

However, a surprising number of decisions do have potential legal implications. Deciding what agreements to enter into, what precautions to take while driving, what taxes to pay, what financial arrangements to make for one's heirs, how to communicate with one's landlord, how to sort one's recyclable garbage, and so on are all examples of legally relevant decisions. In fact, some decisions 
may give rise to multiple legal implications. To take just one example, an individual who decides to drive above the posted speed limit faces both potential criminal liability (for violating the state's traffic laws) and a higher likelihood of civil liability (by engaging in unreasonable driving behavior, she is both more likely to cause harm to another and more likely to be held responsible for that harm).

For law to influence behavior, individuals must have some knowledge of what the law is. This invites consideration of the nature of markets for legal information. The demand side of this market consists of the individuals and associations who seek legal information. We begin with a look into the nature of this demand. How are ordinary citizens likely to act when their behavior may be subject to the law? We next explore how ordinary citizens are likely to learn about the law in those rare instances where they feel they must do so in order to know how to act. Thereafter we consider the supply side of legal information, focusing on how the state may seek to communicate law to its intended audiences. The state may seek to publicize its own rules or may delegate this task to a corporation (as in a German recycling example that we explore at some length). Important intermediaries in the supply of legal information might also include the news media, trade associations, lawyers, producers of legal software (e.g., tax preparation software), and so on. Finally, we explore two sets of policy implications: (a) how psychology can simplify the way the law is represented and (b) how psychology can induce greater compliance with the law. We conclude with some caveats.

\section{THE DEMAND SIDE OF LEGAL INFORMATION}

\section{How Do We Decide to Act under Laws?}

An individual considering taking an action may employ heuristics to locate a normative rule or rules that might govern the permissibility of that action. The task has a cognitive and a normative side. The individual must learn about the contents of the rule, and she must be willing to comply with what she has learned. Suppose, for example, that a professor is considering whether or not to make photocopies of a journal article for a class of twenty university students. In the United States, if the article is protected by copyright (as most journal articles are), in the ordinary case the applicable legal rules ordinarily require that the author obtain permission in advance from the owner of the copyright. ${ }^{1}$ If the professor's decision objective were to call for both consulting the law and complying with the law under these circumstances, there would be little unconsented photocopying of this sort. In fact, however, such unconsented photocopying is rampant. This suggests that ordinary citizens often make legally relevant decisions without consulting the law. What, then, do they do?

$1 \$ 53$ III Urhebergesetz [German copyright law] under certain conditions entitles teachers to make copies and to hand them out to their pupils. 
Undoubtedly, citizens will behave differently depending upon the context and circumstance. Ellickson (1991) has developed a useful framework for thinking about the sources of authority individuals might consult. According to Ellickson, citizens consult five sources of authority, some of which are firstparty, some second-party, and some third-party.

First, there are the first-party personal ethics that a person may impose on himself. Professors might decide not to photocopy because they regard unconsented photocopying as immoral and would feel guilty if they violated their own moral standards. As Cooter (1997) has forcefully argued, much of behavioral control occurs in this manner-through the enforcement upon oneself of norms internalized during childhood (see also Posner 2000).

Second, actors sometimes enter into contracts that govern their behavior in particular situations. These contracts provide second-party rules of conduct. More generally, such rules can result from any form of reciprocal exchange, be it legal or not (the large literature on reciprocity includes Fehr et al. 1997; Schlicht 1998). A person who breaches a reciprocal relation commonly fears that the promisee will exercise self-help to remedy that breach. Thus, in the unusual situation where the hypothetical professor had previously entered into a governing contract with the copyright owner, the professor's heuristics might direct the professor to consult that contract to find the rules governing photocopying privileges.

The remaining three sorts of rules all are third-party rules. That adjective is descriptive because these rules are created by persons other than the immediate parties to the controversy - in this instance, by persons other than the professor and the copyright owner. The social norms, which diffuse social forces create, are in many situations a powerful instrument of social control. A professor who had openly violated academic norms restricting photocopying of copyrighted work could expect to feel the sting of negative gossip and even ostracism by peers. In the U.S., academic norms permit the unconsented photocopying of a copyrighted journal article for a small number of students. Although the law does not, professors regard this as a permissible "fair use," in part because it greatly facilitates the free exchange of ideas. Academic norms in the U.S. do not, however, permit a professor to photocopy, for example, more than half of a book that the professor readily could have arranged for his students to buy in advance at the university bookstore.

Organizations other than governments also can create rules. The professor's university, for example, might have its own organizational rules governing photocopying of copyrighted work on its machines. This is another type of thirdparty rule.

Finally, the state through its legal system may create normative rules, that is, laws. While a state may aspire to make its laws paramount, in many contexts, citizens, when they turn to rules to help guide their own behavior, will look to rules other than law. When they consider photocopying, most professors apparently consider law an inferior source of rules. 
What situational cues prompt an actor to look to one or another of these various sources of normative rules? An actor is highly unlikely to look to the legal system when both the stakes of a controversy are low (cf. Kirchgässner 1992) and the actor is in a continuing relationship with the party on the other side of the impending dispute. For example, in a jurisdiction without rent control, most disputes that arise between a landlord and tenant enmeshed in an ongoing relationship involve only small stakes. Landlords and tenants are likely to resolve informally hassles that arise between them, without invocation of formal legal entitlements. However, in a rent-control jurisdiction (such as Germany or New York City) stakes are higher because the tenant's loss of the apartment would be a more grievous event. In addition, when rent control is in effect, the law greatly limits landlords' power to end the tenancy and tenants in general do not want to leave. With the self-help tool of exit thus denied to both sides, landlords and tenants are less able to operate by personal contract and norms, and the law becomes more important.

By extension, a person's heuristics are most likely to direct him to apply law when stakes are great and the dispute is with someone who is socially distant. Thus, individuals immediately think of law when they are involved in serious traffic accidents, or confront the state itself over an issue such as taxation or immigration.

\section{A Decision-tree Approach for Modeling How to Act under Laws}

Consider the three classes of rules presented: (a) first-party rules (deontic rules: must, ought, etc.) stemming from the actor's ethics; (b) second-party rules of conduct dictated by contracts into which the actor has entered; and (c) thirdparty rules imposed on the actor by society (in terms of noninternalized social norms), nongovernmental organizations, and the legal system.

In a speculative venture, we now attempt to translate these classes of rules into a decision tree that aims to model how people decide what to do in potentially legally relevant situations. This is an admittedly immodest endeavor in that it requires making assumptions about human decision making that are extremely unlikely to be correct in detail. Yet simplistic, false models sometimes allow us to make progress toward explaining phenomena that might otherwise remain inexplicable (Albert 1978). With these qualifications in mind, let us begin the exercise with a bold speculation.

\section{Routinized Action}

Many textbooks and articles on human decision making assert that people constantly make decisions. This common wisdom is almost certainly wrong. In the vast majority of all human activities, we do not make an endless series of decisions but rather circumvent decision making altogether by resorting to 
routinized actions ("habits") and to rules such as "do what I have done before." In addition, the environment (e.g., other actors or constraints in the external world) makes decisions for them. Indeed, second-party rules of conduct may be seen as an instance of delegating decisions to the environment. According to this view, the problem of how to make a decision in situations in which one's behavior has potential legal ramifications is limited to a small subset of human activities. Members of this subset include the decision whether to photocopy copyrighted work for a class and the decision whether to download music from the Internet, both of which are new to the realm of human affairs. Inspired by our taxonomy of rules, our first, tentative decision tree assumes that people proceed through a maximum of four sequential steps (see Figure 21.1).

By way of concrete illustration, suppose an individual is deciding whether to download music from the Internet. If this situation has been encountered many times before, a person is likely to simply what has been done before. If this is new, however, she will initially turn to her first-party rules. A first-party rule that may come to mind in this context is the rule, "Do not steal somebody else's property." Whether this rule can provide guidance depends on whether the rule

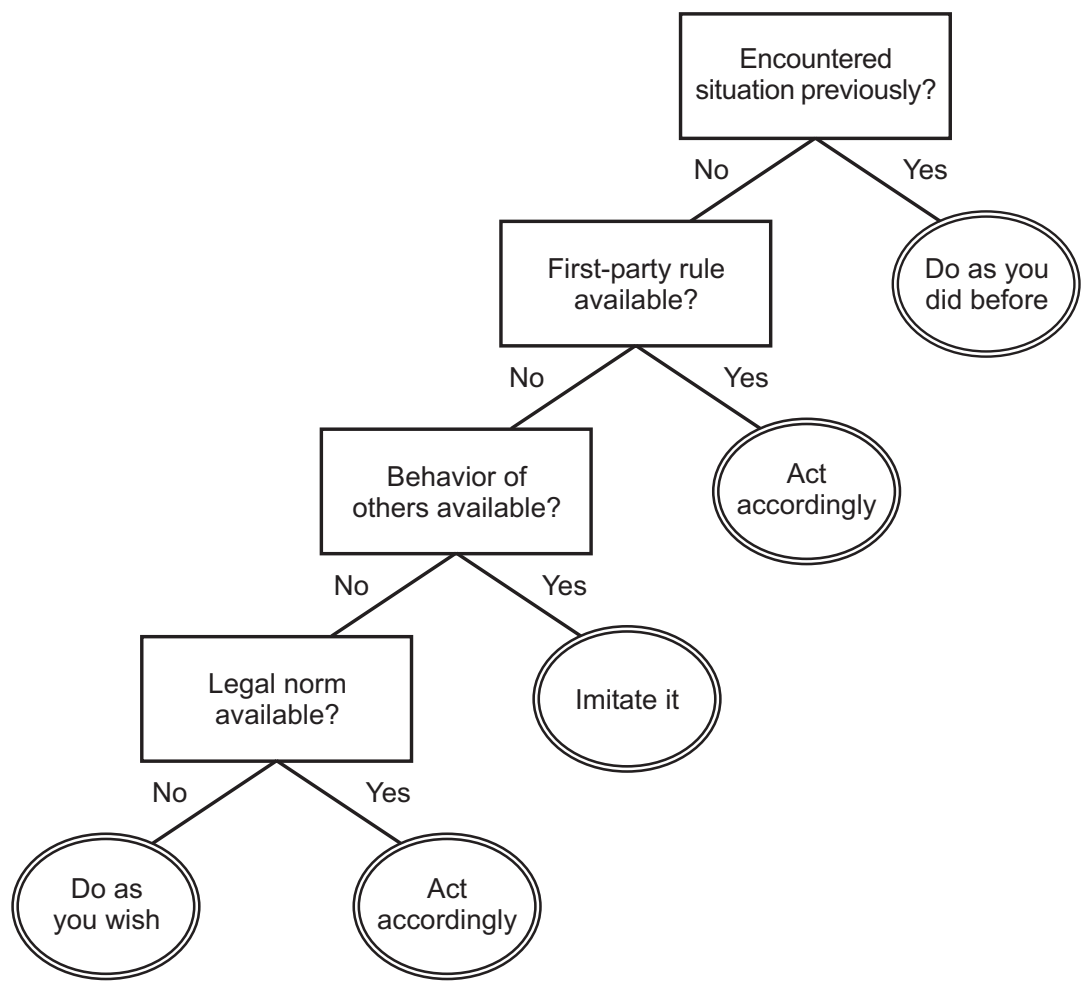

Figure 21.1 A speculative decision tree for how to act under laws. 
is applicable in the current context. In other words, the first-party rule comes with auxiliary "matching rules," on the basis of which it can be inferred whether the current context is in the rule's proper domain. Such matching rules consist, for instance, of a set of subjective criteria that characterize the notion of "property." If the current context and cues it emits do not match these criteria (e.g., cues such as "Is it a tangible good?" "Is it in the possession of somebody?" and "Is it publicly accessible?"), it will be inferred that the simple rule is not applicable.

If the potential music downloader's first-party rule does not dictate a course of action, she moves on to the next step in the decision tree, which represents the notion that decisions can be delegated to one's social environment, that is, to other actors. At this stage, the person observes or finds out how other people behave when facing the same situation. Such social referents can include exemplary individuals (e.g., those who have dealt with the situation successfully or enjoy high prestige for other reasons), the person's social network or, more generally, "the crowd." Returning to the previous taxonomy of rules, one may even speculate that third-party rules that take the form of social norms are proxies for the crowd's behavior because they enable a person to predict it reliably and accurately without observing it. If information about others' behavior, whether inferred from social norms or observed firsthand, is available, the person reaches a decision at this stage: specifically, she copies the behavior of others. For instance, if they download music from the Web, she will too.

Only if consulting her social environment does not render a decision possible - because, for instance, the crowd is split or there are no other actors - she will move on to the fourth step in the decision tree. At this point, she will bother to find out which legal rule (legal rules being a subset of third-party rules), applies in the current context and will conform to it. If no legal rule is found, then she will do as she wishes.

This decision tree, which has the structure of a fast and frugal tree (Gigerenzer, this volume), suggests that the legal system is a last-resort decision module that is consulted only if all other modules (e.g., habits, internal norms, others' behavior) fail to render a decision. It also implies that in many contexts we may not know what the relevant legal rule is because there is no need to discover it (unless one reaches the final stage). Finally, it assumes that there is no integration across decision steps: As soon as a given step enables the person to decide, she will make the decision on that basis, ignoring considerations that would have mattered had she progressed through the later steps.

\section{A Decision-tree Approach in the Domain of Tort Law}

Here we attempt to apply this decision tree to two legally relevant decisions individuals are often called upon to make: deciding whether to take some precaution that might prevent harm against others and deciding what speed at which to drive. 
The law of torts governs civil wrongs other than contracts (Keeton et al. 1984). Most tort cases involve accidents in which one party inadvertently injures another, like automobile accidents, slips-and-falls, and malpractice. For purposes of illustration, suppose that an individual is contemplating whether to take a precaution to avoid tort liability. Suppose, specifically, that an individual homeowner lives in a single-family home with a sidewalk that extends across the front of his land. Suppose further that individuals from within and outside the neighborhood occasionally walk on this sidewalk. Finally, suppose one morning that the homeowner discovers that it snowed several inches the previous night, and he must decide whether to shovel the snow off the sidewalk to decrease the likelihood that a passerby might be injured (and thereby subject him to liability under tort law). How will the homeowner decide?

\section{A Rational Choice Approach}

"Negligence" is the body of law that purportedly regulates this conduct. To determine whether a defendant is liable for harms negligently caused another, the law usually applies the so-called "reasonable person" standard rather than a fixed rule like a posted speed limit. According to this standard, an individual is liable for harms caused to another if he failed to behave as a "reasonable person would have behaved under the same or similar circumstances" (Keeton et al. 1984).

Law and economics scholars (and a famous judge named Learned Hand) have interpreted the reasonable-person standard to embody the tenets of rational choice theory. From their perspective, a prospective defendant should (and will) make an economically rational decision about whether to take a precaution to protect against some harm he might cause. If the costs of prevention exceed the benefits of prevention (which are measured by multiplying the probability of the potential harm by the magnitude of that harm), the defendant should not take the precaution, and if the harm results, he should not be held liable. If, however, the costs of prevention are lower than the benefits, the defendant should take the precaution; if he does not, and if the harm occurs, he should be held liable (Posner 1972; United States v. Carroll Towing Company). Law and economics scholars generally argue that this is normatively appropriate (net social benefits will exceed net social costs, leading to efficient outcomes) and descriptively accurate (because the common law tends toward efficiency).

In this example of shoveling the walk, the homeowner following the dictates of rational choice theory will (and should) make an economically rational decision about what to do, carefully balancing the costs and benefits of shoveling (or not) the snow. But how is the homeowner to value the costs and benefits? How is the homeowner to assess the likelihood that harm will befall someone if he does not shovel the snow? What harm could he reasonably anticipate would come to a pedestrian injured in the fall? These questions - and the calculations they require - seem beyond the ken of most individuals. Instead of engaging in 
economically rational calculation, we believe ordinary citizens employ, implicitly, a heuristic-based approach to determine how to behave. Below, we use the heuristic-based decision tree developed above to describe how an ordinary citizen might decide whether to take precautions to prevent against harm to another, like the potential harm in this hypothetical case.

\section{A Heuristic-based Decision-tree Approach}

Note that the decision tree presented here considers cues that are differently ordered than the decision tree presented in the previous section. The law covers a tremendous range of human behaviors from jaywalking to homicide; any model that would cover all domains would be too general to be useful in prediction. Our analysis is necessarily tentative and might vary for different individuals in different places under different circumstances.

At the outset, we speculate that our individual homeowner will do what he has done before if he has been confronted with this decision in the past. In other words, we believe he will simply defer to habit or routinized action. If habit does not dictate how to behave, we believe he will proceed as follows, as depicted in Figure 21.2.

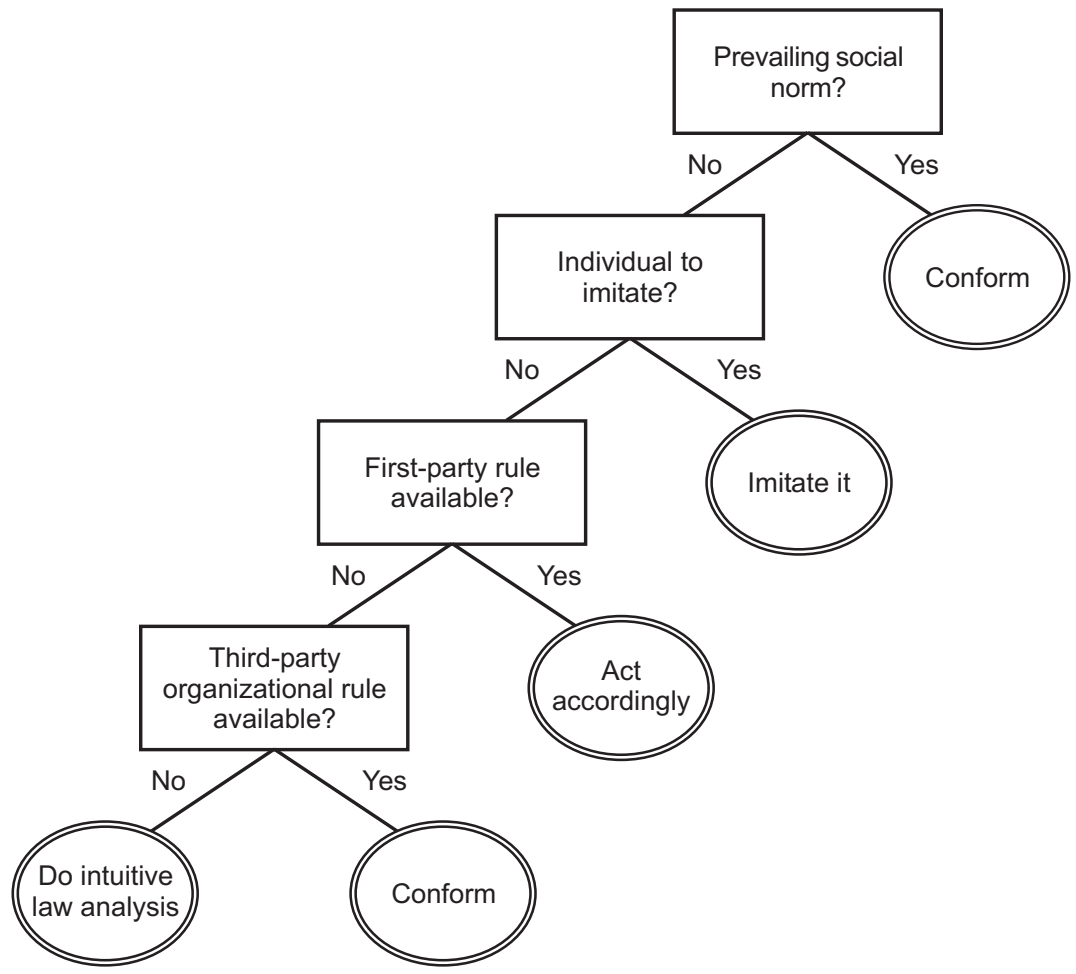

Figure 21.2 A speculative decision tree in the domain of tort law. 
He will conform to the prevailing social norm and imitate the actions of other homeowners in his neighborhood. If there is no prevailing social norm - that is, if the norm is ambiguous - he will attempt to choose between norms by imitating the behavior of the homeowner located closest to him, the homeowner whom he most respects, and/or the homeowner with whom he has the closest relationship. If his attempt to choose between norms is unsuccessful, he will consult his own personal morality, that is, a first-party rule. If his moral code does not dictate a particular decision in a case like this, he will investigate and conform to applicable third-party organizational rules, like the rules governing the homeowners' association (although the apparent variety of behavior on the part of his neighbors may prevent him from complying with any rule requiring him to shovel snow). If the organizational rules do not dictate his behavior, he will conduct an informal and intuitive legal/economic analysis (i.e., he will conduct a rough cost-benefit analysis and unwittingly seek to comply with the governing law, but he will not research the law or seek the advice of a lawyer).

This analysis is incomplete, contestable, subject to individual differences, and undoubtedly affected by context. For example, how might our homeowner's decision be influenced by a spouse requesting that he shovel the sidewalk? Or how might his decision differ if those who normally walked on his sidewalk were young children or the elderly?

Despite these flaws, we believe the analysis supports three interesting propositions for the emerging "heuristics and law" dialogue. First, we believe that individuals are likely to use heuristics or decision rules when making legally relevant decisions (e.g., "conform to applicable norms"). Second, we expect that the law will be less important than many legal scholars assume, particularly for non-expert decision makers. Finally, we doubt that most decision makers will base their decisions on an elaborate, complete, and quantitative rational choice model - a topic we look at in closer detail next.

\section{A Decision-tree Approach in the Domain of Traffic Law}

Traffic laws govern the roadways, including the speed at which a citizen may drive. The law specifies speed limits for different roads (or different stretches of the same road), posts those speed limits, and authorizes police officers to enforce those laws, generally by giving them sanctioning power. How does a driver decide what speed to drive in light of these laws?

\section{An Optimization Approach}

All optimization requires the specification of an objective function to optimize. The objective function can be chosen to optimize one or several criteria. In the simplest case, suppose the driver has only one goal: minimize the cost of 
speeding tickets. To simplify the matter, consider the case of driving in good weather with good road conditions and posted speed limit signs. In the absence of police error, the only way to be sure to avoid being fined for speeding is to drive the speed limit or lower. Given the assumed goal function, this is an optimal strategy. Will optimization be so simple in more realistic scenarios?

Few drivers elect never to exceed the speed limit; most care about the time spent traveling as well. An optimizing strategy for two or more criteria requires the specification of a function relating them. Perhaps this joint criterion would have the form:

$$
W_{1} Y_{1}+W_{2} Y_{2}
$$

where $Y_{1}$ is the cost of speeding tickets over the course of a year, and $Y_{2}$ is the time spent commuting in the year, and $W_{1}$ and $W_{2}$ are the relative weights of the two concerns. Is one hour saved worth $\$ 5$ in fines, or $\$ 50$ in fines? An infinite set of weights is possible. Similarly, the relationship between cost of tickets and time spent traveling may have another functional relationship:

$$
W_{1} Y_{1} \cdot W_{2} Y_{2} \text { or } W_{1} Y_{1}^{W_{2} Y_{2}} \text {. }
$$

Assuming the simple linear relationship holds, we would now need to let our optimization procedure have access to information relating driving speed to driving time, as well as relating driving speed to expected cost of tickets. This, however, is not so simple. The expected cost of tickets depends on the likelihood of getting pulled over, which depends on visual cues indicating the presence of police, the time of day, local knowledge, and even time of month (as ticket writers have quotas). Assuming all this were known well enough to specify the driving-speed to ticket-cost relationship, an optimizing procedure could be carried out, on a computer at least.

Interestingly, this analysis reveals that where violations of the law are concerned, there is always a minimum of two criteria that need to be combined for optimization purposes: the benefit of the violation (e.g., reducing driving time) and the cost of the sanction (e.g., paying a fine).

Why stop with thinking about speed and cost of tickets? Certainly the number of tickets is also relevant. Both in the U.S. and in Germany, a license is suspended after a certain number of "points" are accumulated. The likelihood of getting in an accident matters not only to our health and our wallets, but also to our conscience. Few realistic scenarios are worse to imagine than our behavior taking an innocent life. In addition to these practical concerns, driving speed may serve ineffable criteria. We exceed the speed limit not only to save time, but to alleviate boredom, challenge ourselves, seek distraction, learn about the performance of our automobile, and other concerns that elude the modeler's grasp. If these factors cannot be functionally specified, how can they be optimized? Table 21.1 spells out considerations involved in one-, two-, and multiple-criteria optimizations. 
Table 21.1 Considerations in what an optimizing approach for determining driving speed would entail in increasingly complex models.

\begin{tabular}{|c|c|c|c|}
\hline & $\begin{array}{l}\text { One-criterion } \\
\text { optimization }\end{array}$ & $\begin{array}{l}\text { Two-criteria } \\
\text { optimization }\end{array}$ & Multiple-criteria optimization \\
\hline Target(s) & $\begin{array}{c}Y_{1}: \text { Cost of } \\
\text { speeding } \\
\text { tickets }\end{array}$ & $\begin{array}{l}Y_{1}: \text { Cost of speeding } \\
\text { tickets } \\
Y_{2}: \text { Commute time }\end{array}$ & $\begin{array}{l}Y_{1}: \text { Number of speeding tickets } \\
Y_{2}: \text { Cost of speeding tickets } \\
Y_{3}: \text { Commute time } \\
Y_{4}: \text { Number of accidents } \\
Y_{5}: \text { Cost of accidents } \\
Y_{6}: \text { Likelihood of injuring another } \\
Y_{7}: \text { Likelihood of injuring self } \\
Y_{8}: \text { Enjoyment of driving }\end{array}$ \\
\hline Cues & $\begin{array}{l}\text { Speed-limit } \\
\text { signs }\end{array}$ & $\begin{array}{l}\text { - Speed-limit signs } \\
\text { - Cues for presence of } \\
\text { police cars and asso- } \\
\text { ciated probabilities: } \\
\text { time of day, likely } \\
\text { hiding places, day } \\
\text { of month, local } \\
\text { knowledge } \\
\text { - Expected cost of } \\
\text { tickets given rate of } \\
\text { speed }\end{array}$ & $\begin{array}{l}\text { - Speed-limit signs } \\
\text { - Cues for presence of police cars } \\
\text { and associated probabilities: } \\
\text { time of day, likely hiding } \\
\text { places, day of month, local } \\
\text { knowledge } \\
\text { - Expected cost of tickets given } \\
\text { rate of speed } \\
\text { - Cues for likelihood of accident } \\
\text { and associated probabilities } \\
\text { - Expected cost of accidents given } \\
\text { rate of speed } \\
\text { - Components of driving pleasure, } \\
\text { if definable }\end{array}$ \\
\hline $\begin{array}{l}\text { Optimi- } \\
\text { zation } \\
\text { possible }\end{array}$ & Yes & $\begin{array}{l}\text { Yes, if a function } \\
\text { specifying the rela- } \\
\text { tionship between } Y_{1} \\
\text { and } Y_{2} \text { is precisely } \\
\text { specified and proba- } \\
\text { bilities are known }\end{array}$ & $\begin{array}{l}\text { Unlikely, as a function specifying } \\
\text { the relationship between the vari- } \\
\text { ables would be difficult or impos- } \\
\text { sible to isolate }\end{array}$ \\
\hline $\begin{array}{l}\text { Optimal } \\
\text { strategy }\end{array}$ & $\begin{array}{l}\text { Drive at or } \\
\text { below speed } \\
\text { limit }\end{array}$ & $\begin{array}{l}\text { - Maximize objective } \\
\text { function } \\
\text { - Obtain a function } \\
\text { relating driving } \\
\text { speed to cues } \\
\text { - Drive according to } \\
\text { function }\end{array}$ & Unlikely \\
\hline
\end{tabular}

\section{A Fast and Frugal Approach}

In contrast, consider a heuristic approach to determining driving speed. Such an approach will probably not find the best speed at which to drive in order to 


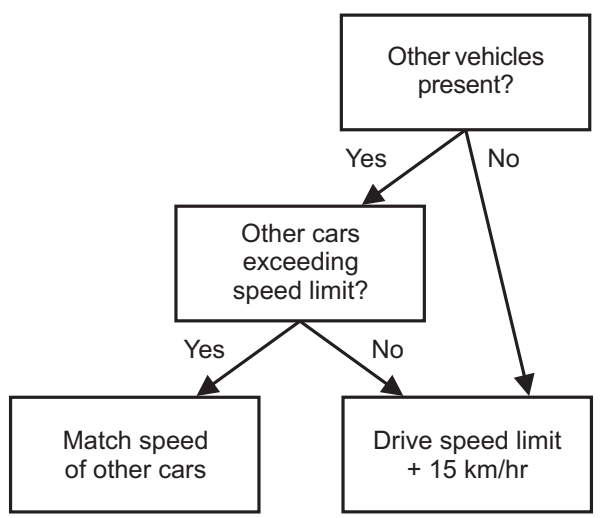

Figure 21.3 A heuristic for determining driving speed under good weather and road conditions.

minimize ticket cost or driving time. Unlike the optimizing approach, the heuristic approach can be easily carried out by the unaided mind. Additionally, it may find a solution that is in the neighborhood of that determined by optimizing means.

A model determined from the authors' introspection is spelled out in Figure 21.3. If there are other cars on the road, check to see if they are exceeding the speed limit. If so, match their speed; if not, drive $15 \mathrm{~km} / \mathrm{hr}$ over the posted speed limit.

At first blush, we thought that a strategy that leads to no tickets would be too conservative. Interestingly, while this strategy is not overly conservative, it will probably result in no tickets. This points out another difficulty of an optimizing approach: one must accurately state one's preferences for an objective function, when doing so is hardly a natural task. Legal scholars and psychologists alike would not be surprised to find that stated preferences for functional relationships contradict what is revealed by behavior.

This heuristic is not optimal. It will not minimize a function relating driving time, exposure to ticketing, likelihood of accidents, or other variables. However, it is a rule that is easily implemented, and it may find solutions close to those determined by optimizing procedures under a variety of parameter combinations.

\section{HOW DO WE LEARN ABOUT LAW?}

Some laws constrain us, such as safety regulations and the criminal code. To avoid legal sanctions, people need to conform to these laws. Other laws enable us to accomplish our ends, such as contracts and wills. Sometimes people can conform to laws or use law for their ends without knowing much law, and sometimes people need to know a lot about laws. Modern law is so massive that most people know something about parts of it and nothing about much of it. For 
example, most people know something about traffic regulations and nothing about securities regulations. The previous section suggested that law is often a relatively unimportant source of guidance when we are called upon to make legally relevant decisions (for more on this conjecture, see Hertwig, this volume). Nonetheless, we do, in some circumstances, attempt to learn about the law. This part explores how we might do so, focusing on cues that indicate to us that our conduct may have legal implications.

\section{Cues to Invoke Awareness of the Law: Social Norms}

We begin by discussing the cues that alert a person to the need to learn something about law. The first cue comes from social norms. A good political and legal system raises selected social norms to the level of legal obligations. For example, the obligation to keep promises is raised to the level of legal obligations when the promise constitutes an enforceable contract. Insofar as law tracks social norms, the socialization process that teaches morality directly also teaches legality indirectly (Engel 2004). By tracking morality, law decreases the amount that people need to learn in order to know the law, and law also aligns with peoples' sense of fairness.

When law tracks morality, the fact that an action impinges on a social norm provides a cue to a person that the action also impinges on the law. For example, the fact that a businessman has a moral obligation to keep a certain promise is a cue that he might also have a legal obligation to keep it. Fairness is another cue for legality (cf. Fehr and Schmidt 2000). Similarly, the recognition that a course of action may result in social conflict, especially conflicting claims of fairness, suggests that it might cause litigation.

Social norms have an internal and an external dimension, which corresponds to internal and external cues about legality. The internal cue is conscience. When a person feels that his action contravenes morality, he is alerted to the possibility that his action might contravene legality. Guilt is a cue for illegality.

Is the use of guilt a heuristic? Morality consists in simple rules that are usually stated without exceptions and without instruction on how to balance competing values. The Ten Commandments, for example, have this character. This fact is consistent with the maxim in adaptive heuristics that "less is more" (Goldstein and Gigerenzer 2002). Cognitive psychology might be used to explain why moral rules are so simple. The explanation might help to explain the advantages of designing law to track morality and improve the ability of lawmakers to design laws that track morality.

The external cues about socials norms consist in the behavior of other people. Social norms usually describe what most people do. In so far as law tracks social norms, people can usually succeed in conforming to the law by doing what others do. The maxim, "do what others require of you do" has been the subject of research by social psychologists for many years; see the work of Bandura (1986) or the work of Asch (1956) on conformity. 
Besides describing what most people do, social norms usually describe what most people think that everyone ought to do. Consequently, many people will apply social sanctions such as criticism or worse against other people who violate social norms (Fehr 2000). Loss of reputation is a powerful deterrent for many people.

\section{Size of Stakes}

We have explained that social norms provide a simple guide to laws that track morality, even to very complex laws such as the law of contracts. Social norms reduce conflict by controlling the interaction of people. The state has a special responsibility to dampen conflicts and redirect them into courts for resolution. Reducing conflict provides a reason for the state to take a special interest in disputes with large stakes. Consequently, the size of the stakes in a potential dispute is a simple cue that behavior is legally relevant. For example, the "statute of frauds," which is an ancient English law with many modern variants, requires promises above a certain value to be written in order to qualify as enforceable contracts. Thus a promise to sell a house for a given price is unenforceable until embodied in writing. ${ }^{2}$

\section{Potential of Harming Others}

In a liberal society, social norms that get enacted into law are the ones that prevent people from harming others. This is true for crimes and accidents. The possibility of hurting someone else is thus a cue that law regulates the behavior in question. We expect to have to learn about laws regulating actions that endanger others. For example, acquiring a driver's license typically requires taking an exam that includes questions about traffic laws.

\section{Long-term Relationships}

In general, law provides a mechanism for punishing wrongdoing. Long-term relationships between people also provide a mechanism to punish wrongdoing by the other party. To illustrate, the strategy of "Tit-for-Tat" means, "repay pain with pain, and repay pleasure with pleasure." Long-term relationships provide scope for the parties to use such strategies for punishing wrongdoing. Since law and relationships are substitutes for each other, law often restricts the scope of its interference in relationships. For example, most aspects of the relationship among family members are uncontrolled by law. Consequently, people who are in long-term relationships tend not to resort to the law to resolve their disputes. To illustrate, if the husband in a traditional marriage promises to be home on time for dinner, his late arrival does not prompt his wife to sue for breach of

2 The same holds in Germany, according to $\$ 311 \mathrm{~b}$ I Civil Code (Bürgerliches Gesetzbuch). 
contract, but he may find that she has already eaten and his food is burned. The existence of a long-term relationship is a cue that law may be practically irrelevant to behavior.

Conversely, the absence of a long-term relationship is a cue for the need to understand the law and invoke it. To illustrate, real-estate purchases typically involve high stakes and no relationship between buyer and seller. Knowing these facts, few people are so foolish as to enter a real-estate contract without receiving expert advice from a lawyer or a real-estate broker.

\section{Verifiability}

Another important cue for law is verifiability, by which we mean "provable to a tribunal." When acts are difficult to verify, laws and contracts have difficulty controlling the acts. To illustrate, laws against "date rape" are often ineffective because the parties are the only witnesses, and they provide conflicting testimony. Some acts are difficult to verify because the affected parties cannot observe them. The observable nature and verifiability of an act are cues that law may control it.

\section{HOW DOES THE LAW REACH ITS ADDRESSEES?}

We have focused on the demand for legal information, both how people make legally relevant decisions and how people receive cues indicating that they should turn to the law for guidance. Now we turn our attention to the supply of legal information. In this part, we explore how the law reaches its intended audience.

Government institutions, including schools, provide citizens with some information about the law. Indeed, the democratic ideal that law is public implies some publicizing of it. For example, important trials are widely reported in the newspaper or even televised in some jurisdictions. Perhaps the trial of O.J. Simpson increased the knowledge of legal procedure among Americans more than any other event in recent years.

Besides the state, the legal profession is another major source of professional information about the law. Lawyers in many countries still work under laws that severely limit their ability to advertise their services and otherwise inform the public about what they do. A vigorous attack on these restrictions as monopoly practices that harm the public resulted in large changes in the legal profession in some jurisdictions, including the U.S. Advertising is especially intense where restrictions have been removed and lawyers are allowed to work on contingency fees, as in the U.S. The contingency fee system directs lawyers to disseminate relatively accurate information about law to uninformed people with potentially large claims. Advertisers are very familiar with the principles of cognitive psychology, which are now put in the service of attracting business for lawyers. For example, television advertising in the U.S. promotes the simple heuristic, "If your property or person were injured in an accident, then call a lawyer." 
Computer programs and the Internet have provided cheap sources of legal advice and algorithms to simplify the solution to legal problems, such as filing income tax returns.

The legal documents that lawyers produce are often directed at courts, not at citizens. For example, the warnings on pharmaceuticals are probably more effective at avoiding liability than conveying information to consumers. If these warnings used heuristics more and relied less on a comprehensive list of side effects, the law would communicate more information to the users of drugs. Laws that require effective communication, not just comprehensive and logical presentation of information, can increase information about the law.

Below we take a close look at one example of the law reaching its intended audience through an intermediary. Germany has given high priority to treating waste in an environmentally friendly way (the following builds on Lüdemann 2004). It believes in recycling, rather than disposal. The highest rank is given to recycling in kind, and with one waste fraction, plastics, this is demanding. If the goal for recycling in kind is set significantly above $50 \%$, recycling industrial waste is not enough. The regime must be extended to waste originating in households. Household waste comes in comparatively small amounts. Traditionally, there was just one dust bin per household, or even per block. The recycling quota for plastics can only be met if households separate waste. There is indeed a rule in the waste management statutes of many German states to this effect, but it is beyond doubt that this is merely law in the books. It would even be constitutionally questionable if governmental officials poked around in citizens' dustbins. More importantly, the transaction costs would be prohibitive. The only realistic option was putting the separation of waste into people's minds.

This is indeed what has happened. More precisely, this is what government has brought about by a clever scheme. The scheme starts out from an entirely different angle. Recycling in kind is costly. Having each household pay for the cost of recycling by the unit of packaging waste is a practical impossibility. The transaction cost would be prohibitive. More importantly, it would entail a counterproductive incentive for littering. Hence the government wanted to add the price of recycling to the cost of purchasing the packaged product. However, assessing this cost poses a severe information problem. The solution is a monopoly called the Duales System Deutschland (DSD). It collects the money from the producers of packaged products, and it uses this money to pay for recycling. Inside the company, both the producers and the recycling industry are represented. Year by year they negotiate the recycling price separately for each waste fraction, handing the problem of information generation thus over to negotiation. The legal monopoly is, however, conditional upon outcome. It vanishes if DSD no longer meets the fairly high recycling quota.

Bringing about a sufficient degree of waste separation in the households is therefore paramount for the very existence of this monopoly and, indirectly, for all producers who sell packaged goods. DSD has responded by investing 
heavily into advertising. Thereby, every German knows that she is expected to separate her waste. Most households do not only have separate bins in the backyard. They also keep separate collections in the kitchen. Actually, the rule followed by most households is a simple heuristic. If merchandise is packed in plastic, put the package into the yellow bin. The correct rule would be: if it carries the sign for having paid the DSD, which is a green dot, then it should go into this bin. Because not all plastics are marked with this green dot, DSD has to handle more than $10 \%$ of waste they would not be obliged to process. They accept this, since transmitting the more complex, correct rule might generate too much complexity and uncertainty and thereby endanger the overall recycling quota. Even most lawyers do not know that there is indeed also a legal obligation to separate. It is never enforced. Separating waste has meanwhile almost become a definitional element of the German national character. The good citizen is a person who correctly separates the proverbial yogurt container into the plastic fraction (the beaker) and the aluminum fraction (the lid). Originally, children learned this in kindergarten, and subsequently educated their parents. By now, separating has become so natural that most Germans no longer feel any obligation. Behavior that was originally guilt driven, after being turned into a morality issue, has now become a mere habit, an element of the German culture, much like drinking beer or driving fast on motorways.

A second example exhibits a very different behavioral pattern. It again is taken from the German legal order. In Germany, tenants are strongly protected. Business premises notwithstanding, a landlord cannot simply give the tenant notice. Basically, he has this right only if he can prove that he himself wants to move into the flat. This typically turns the rental contract into a long-term relationship. Now the price level for flats changes over time, as does the cost for building houses, and for maintaining them. A complex set of legal rules therefore regulates under which conditions the landlord is entitled to raise the rent. This set of rules creates a natural tension between landlord and tenant. It explains why many landlords, as well as many tenants, have a fairly developed knowledge of the pertinent legal rules. Quite a few do indeed read the text of the statute. Others glean this information from their peers, especially after a bad experience. Still others precautionarily become members of landlords' or tenants' associations, just in case they might need legal help one day.

\section{POLICY IMPLICATIONS}

\section{How Can Psychology Simplify the Presentation and Representation of the Law?}

\section{User-friendliness}

Software is more complicated than it was 25 years ago, yet software is also easier to use than it was 25 years ago. The statements seem to contradict one 
another, and nevertheless both are true. Software has to be functional at two levels: the internal mechanism responsible for adequate outputs depending on the inputs is one side of the coin. Modern software for word processing is so advanced that one can publish a whole book on a desktop computer. Twenty-five years ago, no manufacturer would have tried to implement such complexity within a single program. The other side of the coin is the user interface. Software has become easier to handle than it was 25 years ago when there was no mouse, no graphical icons to click on, and no menu bars. Nowadays, we have easy-tohandle software with complicated machinery behind it - at least this is how we expect that software should be.

There are several similarities between this example and the law. Law is also complex. It has to coordinate action, it has to help prevent serious conflicts, it should give orientation, and have an expressive function. Law integrates many special tasks that concern only a small subset of its addressees. Law has to be functional in its machinery. The analogy to software suggests another issue. Despite its complexity in order to achieve adequate functionality, law should be easy to handle for the addressees. It should be user-friendly. Lawmakers might sympathize with the problem of making complex laws easy to use for the addressees, but they feel that this problem is outside of their area of expertise. They need some psychological insight in order to make law user-friendly, in domains where user-friendliness is desirable.

A first idea how this goal could be achieved might be that the addressees should "intuitively" do the right things. According to this idea, the design of rules should be such that they are very easy to comprehend and to apply. This goal can be achieved by focusing on different psychological mechanisms: behavioral (stimulus-response), cognitive (analogies, framing, conversational maxims, statistical formats), social (ostracism and cheater detection). How and when these mechanisms can be applied depends on whether social norms are in congruence or at odds with the law.

\section{Behavioral Mechanisms}

Behavioral strategies try to modify the physical environment in a manner such that these modifications are stimuli for the addressees that lead to the desired responses (cf. Skinner 1938). Consumer psychology is a prominent field that mainly focuses on the usage of behavioral mechanisms (Norman 1988). The placement of goods in a supermarket is based on the assumption that most people tend to go counterclockwise in a circle around the store. Knowing that, the merchant strategically places goods where he thinks that people might spontaneously buy them within this circle. Goods that people really need in everyday life are placed elsewhere. Additional stimuli (like "special offers" with canceled old prices) augment the probability that clients will buy the product. Knowledge of how people interact with a particular environment might allow for 
innovations that promote adherence to the law. Certain road markings, for instance, have been designed in order to give the subjective impression of an increase in speed even when speed is held constant, and thus make people correct their own speeding behavior. Another example would be cars that can only be started after the seat belt has been fastened. The physical environment can be shaped in a fashion that it guides the addressees to the desired behavior.

\section{Cognitive Mechanisms}

Framing. One and the same situation may lead to different behavioral results depending on the frame where the situation is embedded (Kahneman and Tversky 2000). For example, framing a prisoner's dilemma game as a "community game" or a "Wall Street game" leads to completely different results (Ross and Ward 1996). So it is not the rules of the game itself (the prisoner's dilemma in this example), but the context in which they are embedded that matters. If the goal of a law is to increase organ donation rates, framing can matter. Depending on whether the default is being a donor or not being a donor, rates of organ transplantation between countries will differ significantly (Johnson and Goldstein 2003).

Similarly, lawmakers can make use of framing effects to motivate healthy behaviors. Health-relevant communications can be framed in terms of gains (highlighting the potential benefits of an option) or losses (highlighting the potential costs of an option). The relative influence of gain- or loss-framed appeals is contingent on the degree to which performing a health behavior is perceived as risky. Illness-detecting behaviors (e.g., cancer screening, HIV testing) are perceived as risky because they can inform people that they may be sick, whereas illness-preventing behaviors (e.g., sunscreen use, condom use) are not perceived to involve risk because they affirm health. Research on the effect of verbal framing has focused on positive versus negative framing and on gain versus loss framing (Tversky and Kahneman 2000). Positive and negative frames refer to whether an outcome is described, for instance, as a $97 \%$ chance of survival (positive) or a $3 \%$ chance of dying (negative). The evidence is that positive framing is more effective than negative framing to persuade people to choose risky treatment options. Similarly, risky options are chosen more often when a loss frame is used (highlighting the potential costs of an option) rather than a gain frame (highlighting the potential benefits of an option).

Analogical Reasoning. When a law is complex, and it is important that the law is understood by the addressee, then analogies might help foster understanding. Comprehending why downloading of music is an infringement of property rights could be facilitated by using an analogy of a store selling music CDs. Taking a $\mathrm{CD}$ without paying at the register is theft. To make analogies successful, a 
careful analysis of the source problem, the relevant objects, and the relations between them has to be performed (see Gentner's structure mapping theory; Gentner and Markman 1997). It must be clear that the mapping from the source problem to the target problem is unique, that is, which object of the source domain has to be mapped onto which object of the target domain. Given that such a unique mapping is possible and that it has been made transparent to the addressees, the advantage of analogies lies in the fact that the relations between the objects of the source domain are automatically (or "intuitively") mapped to the target domain, such that there is an immediate understanding of the structure of the target domain. The analogy of a theft in a CD store in comparison to the downloading of music would probably fail, because from the point of view of the addressee the theft took already place by the provider of the site where he can download the $\mathrm{CD}$ free of charge.

Conversational Rules. Grice $(1975,1989)$ described four maxims of cooperative conversation that guide most of our daily communication processes. As a default, it is assumed that listeners tacitly expect that the speaker will try to meet certain standards of communication. In particular, we assume that information that is given to us is truthful (maxim of quality), relevant to the aims of the conversation (maxim of relevance), clear (maxim of manner), and that the message we receive is as informative as is required, but not more informative than is required (maxim of quantity). If both listener and speaker follow these cooperative rules, the communication process is facilitated. The listener, for instance, does not have to filter the information he gets for relevance if he can trust that the speaker adheres to the relevance maxim.

When maxims of communication are violated, it can end in health risks and lawsuits. The U.S. Food and Drug Administration (FDA) requires pharmaceutical companies to disclose potential negative side effects of medications. To comply with their duty to warn, these companies provide an extensive list of adverse outcomes with each medication, most of which are expected to occur with an infinitesimal probability. Because the list is so long, it is therefore printed in small font size. As a result of these two factors, most consumers do not read the compendium of potential side effects. This may be an example in which more information results in a message that is less clear, less informative, and less relevant than the actual goal of the communication requires. By forcing pharmaceutical companies to list so many side effects, the FDA may actually discourage consumers from reading any of the list. Thus, a more effective warning might be a shorter warning. However, the portion of the list of side effects removed from the primary list should be made available to those consumers who are motivated to read about every possible adverse outcome. Note that the suggestion to shorten the primary list is motivated by recognition of the cognitive or motivational limitations of the consumer. By forsaking the requirement to provide the consumer with complete information, the FDA might instead match the 
information available in the environment to the information-seeking needs of the typical consumer.

An example of the U.S. Federal Trade Commission's (FTC) recognition of the cognitive limitations of the consumer occurred in the "Listerine case" (Harris and Monaco 1978). The manufacturer of Listerine mouthwash did not assert in their television commercial that "Listerine prevents colds." Of course, neither Listerine nor any other brand of mouthwash can prevent colds. However, the manufacturer of Listerine did include in the commercial a number of statements that, as a group, strongly implied this conclusion. An experiment was executed in which the text of the commercial was presented to people. These participants were then asked if the sentence "Listerine prevents colds" had been included in the commercial's text. Every participant mistakenly claimed that this statement had been included. This exemplifies the basis for the FTC action: while explicitly stating nothing that was false, the manufacturer had implied a false conclusion. Due to the fact that people often cannot distinguish what was presented from what was implied (Bransford and Franks 1971), this cognitive limitation led to the participants' faulty memory for the offending sentence. Through their administrative action, the FTC recognized this as an understandable confusion that should not be exploited.

As in the case of the truncated list of potential side effects, knowing about people's cognitive limitations should inform legal requirements for information display. More information will not necessarily foster optimal behavior. The ability to draw seductive but unwarranted inferences confers no advantage.

Statistical Formats. Statistical information can be expressed in many different ways. For instance, the risk of a major side effect associated with a particular medical intervention can be described as happening "very rarely," or "in only $0.5 \%$ of the cases," or "in 50 out of 10,000 cases." Research on statistical thinking has shown that the choice of statistical format has a strong impact on understanding of the information (Gigerenzer and Hoffrage 1995; Hoffrage et al. 2000). In particular, it is easy to confuse people with statements on single-event probabilities (e.g., "You have a $0.5 \%$ chance of a side effect from this drug"), conditional probabilities (e.g., "If you have a positive result in this screening test, your chance of having the disease is $10 \%$ "), and relative risks (e.g., "This screening test reduces mortality by $25 \%$ "). One way to reduce the confusion is to choose alternative representations of the same information that reduce the ambiguity inherent in these statements. Conditional probabilities, for instance, can be better understood if they are represented in terms of natural frequencies (e.g., "Out of 100 people like you who have a positive result in this screening test, 10 have the disease"), because the reference classes of the statistical information is made transparent (Gigerenzer and Edwards 2003). Selecting the format of statistical information is a very simple way of shaping the information environment for the addressees of risk communication. 


\section{How Can We Generate Compliance to Laws, Once They Are Understood by Their Addressees?}

The second type of problem situation encountered by the law, to which knowledge about human psychology might provide some assistance, is the question of how to get people to comply with laws that are well understood (assuming compliance is desirable). This could either be laws that are short and simple (e.g., the requirement to wear a seat belt while driving) or more complex laws in a simplified presentation format, as discussed in the previous section.

While the law has a multiplicity of social or collective distal goals and intentions (e.g., to increase societal efficiency or distributive justice), the state also pursues the more proximal goal of getting its citizens to comply with the law. Rational choice theory implies that compliance with the law will result when the sanctions or penalties for prohibited actions that are specified by the law are well known to citizens, of sufficient magnitude to outweigh the benefits of actions prohibited by the law, and credibly enforced. Noncompliance with well-understood and credibly enforced laws suggests that the specified sanctions, or monitoring, need to be increased. The picture is different if we allow for the possibility that citizens engage in actions that either comply or fail to comply with the law as the result of processes that fall short of comprehensive deliberation and analysis of pros and cons. As discussed, the ideal scenario has citizens engage in the collectively beneficial behavior specified by the law without any conscious deliberation, in a habitual fashion, without any conscious awareness of the possibility of alternative actions (examples: putting on one's seat belt automatically, as soon as one sits down in a motor vehicle; cleaning a plastic yogurt container after consuming its content and putting it into the designated plastics section of the waste disposal area in one's kitchen).

Especially for laws that require simple, relatively noncontingent behavior, there is a good chance that compliance behavior can be automated by following one or more of the following steps. Automation of any behavior requires its execution over a large series of trials (or instances). As discussed in the above section on psychological mechanisms, we have multiple ways at our disposal to motivate people to engage in the socially desirable behavior prescribed by the law. We can, for example, invoke the threat of fines, use social norms and people's fear of embarrassment or social ostracism, or capitalize on people's tendency to imitate the actions observed by others by flooding them with appropriate role models in movies or advertisements, to increase people's likelihood of engaging in the desired behavior (e.g., buckling up) over an extended period of time. While such behavior will initially be consciously or unconsciously calculation based or rule based (e.g., buckling up because of the fear of a fine or because admired actresses do it in the movies), the behavior will eventually become second nature, in the sense of being executed without conscious awareness, i.e., without the realization that not buckling up is an option (for an 
account in terms of learning theory, see Anderson 2000, Chap. 9). Such automatic acceptance of a behavior is typically accompanied by a negative emotional signal if one is prevented for some reason from executing the behavior. A defective seat belt encountered on the back seat of a taxi leaves one feeling unsafe for the duration of the ride, and one's inability to find a plastic recycling bin in the vacation rental in the U.S. leaves one feeling outraged at the lack of environmental awareness of American consumers.

It should be noted that it is easier by a large margin to establish new automatic behaviors than to change existing automatic behaviors. In terms of policy implications, this latter case can be a problem, as we discuss next.

\section{Policy Caveat: Entrenchment of Habit}

Generating a habit can be a powerful tool for bringing about compliance with the law. When law targets the behavior of individuals, this is almost the only route to effectiveness. But before turning that insight into a piece of advice for governance, policy makers should consider the likely cost of this approach. On balance, this cost may well seem prohibitive. If so, the policy maker would want to find more indirect methods, e.g., targeting an industry rather than individuals. Safety belt legislation illustrates the point. As mentioned, some countries have obliged manufacturers to design cars so that it is impossible to turn the ignition key unless all those in the car have fastened their seat belts.

The recycling example used earlier illustrates why the cost of generating a habit may indeed be high. As laid out, German policy makers indeed have been successful in turning Germans into world champions in separating plastic waste. This has been done on the assumption that recycling plastic waste in kind is good for the environment, and that Germany is rich enough to afford the cost. However, there is serious dispute whether the total environmental cost of recycling plastic waste from households does not exceed the benefit to the environment (Giegrich et al. 1999). Esteemed scientists now claim that burning this waste fraction would be preferable. Assume this became accepted wisdom. Society might then want to change back to its previous policy. The cost for doing this, however, might well be prohibitive. Not only would German society have to go through a collective process of unlearning, the waste separation habit has also been established as a highly salient symbol for attitudes toward the environment, if not a visible expression of good citizenship. This policy maker may not want to put this at risk for the small gain of treating plastic waste in an environmentally more appropriate way.

\section{Policy Caveat: Bad Laws}

It is plausible that insights gleaned from the study of heuristics can be applied to make law more effective. Making law more effective commonly enhances 
social welfare. But it need not. If a law is a bad one, it is not wise to make it more effective. Examples of bad laws are easy to find. In the U.S., the Prohibition Amendment departed sharply from prevailing social norms and was increasingly violated as time passed. Americans eventually concluded that Prohibition was a bad law and repealed it after a few years. Similarly, when a well-organized industry successfully lobbies for protectionist legislation, consumers suffer. Making bad laws of this sort more effective is hardly wise.

Moreover, some domains of human life are better regulated by methods of social control other than law. For example, a husband and wife have to work out which of them will cook the meals, take out the trash, and so on. These sorts of decisions generally are better controlled by contract and norm than by law. If a legislature were to be foolhardy enough to pass a law that ordered, say, wives to take out the trash, the legislature would have entered a domain it should not have touched. Analysts who applied their knowledge of heuristics to make it easier for wives to understand this law would not be enhancing social welfare.

\section{CONCLUSION}

How do people decide how to act under laws? How do laws reach their addressees? The theory of the mind as a rational optimizer leaves the answer to these questions in a black box, assuming that changes in behavior will eventually come about if the incentives are right. In this chapter we have discussed a psychologically plausible alternative: models of bounded rationality that use different cognitive and motivational processes in a sequential and contingent fashion and can be described by a simple set of rules or heuristics to navigate a complex legal environment. Understanding people as users of heuristics instead of as optimizers allows for more transparent models that can yield predictions about how laws will be transmitted and when they will be followed - predictions that should be of great concern to those who shape policy.

\section{REFERENCES}

Albert, H. 1978. Traktat über rationale Praxis. Tübingen: Mohr.

Anderson, J.R. 2000. Learning and Memory: An Integrated Approach. New York: Wiley. Asch, S.E. 1956. Studies of independence and conformity: A minority of one against a unanimous majority. Psychol. Mono. 70:1-70.

Bandura, A. 1986. Social Foundations of Thought and Action: A Social Cognitive Theory. Englewood Cliffs, NJ: Prentice Hall.

Bransford, J.D., and J.J. Franks. 1971. The abstraction of linguistic ideas. Cog. Psychol. 2:331-350.

Cooter, R. 1997. Normative failure theory of law. Cornell Law Rev. 82:947-979.

Cooter, R., and T. Ulen. 2004. Law and Economics. Boston: Addison-Wesley.

Ellickson, R. 1991. Order without Law. Cambridge, MA: Harvard Univ. Press. 
Engel, C. 2004. Learning the law. Preprints of the Max Planck Institute for Research on Collective Goods, Bonn. http://www.mpp-rdg.mpg.de/pdf_dat/2004_5online.pdf

Fehr, E. 2000. Cooperation and punishment in public goods experiments. Am. Econ. Rev. 90:980-994.

Fehr, E., S. Gächter, and G. Kirchsteiger. 1997. Reciprocity as a contract enforcement device: Experimental evidence. Econometrica 65:833-860.

Fehr, E., and K.M. Schmidt. 2000. Theories of fairness and reciprocity: Evidence and economic applications. Cesifo Working Paper Ser. 403. http://Papers.Ssrn.Com/ Paper.Taf?Abstract_Id=255223

Gentner, D., and A.B. Markman. 1997. Structure mapping in analogy and similarity. Am. Psychol. 52:45-56.

Giegrich, J., H. Fehrenbach, W. Orlik, and M. Schwarz. 1999. Ökologische Bilanzen in der Abfallwirtschaft: Forschungsbericht 20310606, neu:29431606, UBA-FB 99014. UBA-Texte 10/99. Berlin: Umweltbundesamt.

Gigerenzer, G., and A. Edwards. 2003. Simple tools for understanding risks from innumeracy to insight. Brit. Med. J. 327:741-744.

Gigerenzer, G., and U. Hoffrage. 1995. How to improve Bayesian reasoning without instruction: Frequency formats. Psychol. Rev. 102:684-704.

Gigerenzer, G., P.M. Todd, and the ABC Research Group. 1999. Simple Heuristics That Make Us Smart. New York: Oxford Univ. Press.

Goldstein, D.G., and G. Gigerenzer. 2002. Models of ecological rationality: The recognition heuristic. Psychol. Rev. 109:75-90.

Grice, H.P. 1975. Logic and conversation. In: Syntax and Semantics, ed. P. Cole and J. Morgan, vol. 3, Speech Acts, pp. 41-58. New York: Academic.

Grice, H.P. 1989. Studies in the Way of Words. Cambridge, MA: Harvard Univ. Press.

Harris, R.J., and G.E. Monaco. 1978. The psychology of pragmatic implications: Information processing between the lines. J. Exp. Psychol: Gen. 107:1-22.

Hoffrage, U., S. Lindsey, R. Hertwig, and G. Gigerenzer. 2000. Communicating statistical information. Science 290:2261-2262.

Johnson, E.J., and D.G. Goldstein. 2003. Do defaults save lives? Science 302:13381339.

Kahneman, D., and A. Tversky. 2000. Choices, Values, and Frames. Cambridge: Cambridge Univ. Press and New York: Russell Sage.

Keeton, W.P., D.B. Dobbs, R.E. Keeton, and D.G. Owen, eds. 1984. Prosser and Keeton on the Law of Torts. $5^{\text {th }}$ ed. St. Paul, MN: West Publ.

Kirchgässner, G. 1992. Toward a theory of low-cost-decisions. Eur. J. Pol. Econ. 8:305-320.

Lüdemann, J. 2004. Edukatorisches Staatshandeln. Baden-Baden: Nomos.

Norman, D.A. 1988. The Psychology of Everyday Things. New York: Basic.

Payne, J.W., J.R. Bettman, and E.J. Johnson. 1992. Behavioral decision research: A constructive processing perspective. Ann. Rev. Psych. 43:87-131.

Payne, J.W., J.R. Bettman, and E.J. Johnson. 1993. The Adaptive Decision Maker. Cambridge: Cambridge Univ. Press.

Payne, J.W., J.R. Bettman, and E.J. Johnson. 1997. The adaptive decision maker: Effort and accuracy in choice. In: Research on Judgement and Decision Making: Currents, Connections, and Controversies, ed. W.M. Goldstein and R.M. Hogarth, pp. 181204. Cambridge: Cambridge Univ. Press.

Posner, E.A. 2000. Law and Social Norms. Cambridge, MA: Harvard Univ. Press.

Posner, R.A. 1972. A theory of negligence. J. Legal Stud. 1:29-96. 
Posner, R.A. 2003. Economic Analysis of Law. New York: Aspen.

Ross, L., and A. Ward. 1996. Naïve realism: Implications for social conflict and misunderstanding. In: Values and Knowledge, ed. E.S. Reed, E. Turiel, and T. Brown, pp. 103-105. Mahwah, NJ: Erlbaum.

Schlicht, E. 1998. On Custom in the Economy. Oxford: Clarendon.

Simon, H.A. 1957. Models of Man: Social and Rational. New York: Wiley.

Skinner, B.F. 1938. The Behavior of Organisms: An Experimental Analysis. New York: Appleton Century.

Tversky, A., and D. Kahneman. 2000. Rational choice and the framing of decisions. In: Choices, Values and Frames, ed. D. Kahneman and A. Tversky, pp. 209-223. Cambridge: Cambridge Univ. Press.

United States v. Carroll Towing Co., 159 F.2d 169 (2d Cir 1947). 
